\title{
Activation of Muscarinic Receptors in Rat Bladder Sensory Pathways Alters Reflex Bladder Activity
}

\author{
F. Aura Kullmann, ${ }^{1}$ Debra E. Artim, ${ }^{1}$ Lori A. Birder, ${ }^{1,2}$ and William C. de Groat ${ }^{1}$ \\ Departments of ${ }^{1}$ Pharmacology and ${ }^{2}$ Medicine, University of Pittsburgh School of Medicine, Pittsburgh, Pennsylvania 15261
}

\begin{abstract}
Antimuscarinic drugs affect bladder sensory symptoms such as urgency and frequency, presumably by acting on muscarinic acetylcholine receptors (mAChRs) located in bladder sensory pathways including primary afferent nerves and urothelium. However, the expression and the function of these receptors are not well understood. This study investigated the role of $\mathrm{mAChRs}$ in bladder sensory pathways in vivo in urethane anesthetized rats. Intravesical administration of the $\mathrm{mAChR}$ agonist oxotremorine methiodide (OxoM) elicited concentration-dependent excitatory and inhibitory effects on the frequency of voiding. These effects were blocked by intravesical administration of the $\mathrm{mAChR}$ antagonist atropine methyl nitrate $(5 \mu \mathrm{M})$ and were absent in rats pretreated with capsaicin to desensitize $\mathrm{C}$-fiber afferent nerves. Low concentrations of ОхоМ $(5 \mu \mathrm{M})$ decreased voiding frequency by $\sim 30 \%$, an effect blunted by inhibiting nitric oxide (NO) synthesis with L-NAME ( $N_{\omega}$-nitro-L-arginine methyl ester hydrochloride; $5 \mathrm{mg} / \mathrm{kg}$; i.v.). High concentrations of $0 x 0 \mathrm{M}(40 \mu \mathrm{M})$ increased voiding frequency by $\sim 45 \%$, an effect blunted by blocking purinergic receptors with PPADS (0.1-1 mm; intravesically). mAChR agonists stimulated release of ATP from cultured urothelial cells. Intravenous administration of OxoM $(0.01-5 \mu \mathrm{g} / \mathrm{kg})$ did not mimic the intravesical effects on voiding frequency. These results suggest that activation of mAChRs located near the luminal surface of the bladder affects voiding functions via mechanisms involving ATP and NO release presumably from the urothelium, that in turn could act on bladder C-fiber afferent nerves to alter their firing properties. These findings suggest that the urothelial-afferent nerve interactions can influence reflex voiding function.
\end{abstract}

Key words: urethane; antimuscarinics; urothelium; capsaicin; oxotremorine methiodide; afferent nerves

\section{Introduction}

Antimuscarinic agents are the main treatment for overactive bladder, a condition caused by aging, spinal cord injury (SCI), and other pathologies (Finney et al., 2006). According to traditional concepts, antimuscarinic drugs act by blocking postjunctional muscarinic acetylcholine receptors ( $\mathrm{mAChRs}$ ) in the bladder smooth muscle, thereby suppressing voiding contractions evoked by acetylcholine (ACh) released from parasympathetic efferent nerves (de Groat and Yoshimura, 2006; Finney et al., 2006). However, antimuscarinic drugs affect sensory bladder symptoms such as urgency, suggesting an action on bladder afferent pathways, which could involve a block of mAChRs in the urothelium and/or in the afferent nerves (Finney et al., 2006).

Bladder sensory pathways are potential targets for drugs used to treat various bladder dysfunctions because of their role in irritation symptoms (i.e., urgency, frequency) and in triggering reflex bladder activity (de Groat and Yoshimura, 2006; Birder and de Groat, 2007). Bladder afferent nerves originate in lumbosacral dorsal root ganglia and carry information regarding bladder full-

Received 0ct. 16, 2007; revised Dec. 18, 2007; accepted Jan. 10, 2008

This work was supported by a grant from the American Foundation for Urological Diseases/American Urological Association Education and Research Scholar Program to F.A.K. (Negoita), and National Institute of Diabetes and Digestive and Kidney Diseases Grants 49430 (W.C.d.G.) and 54824 (L.A.B.). We thank S. Zilavy for editorial help and members of the W. C. de Groat and L. A. Birder laboratories for valuable discussions.

Correspondence should be addressed to Dr. F. Aura Kullmann, Department of Pharmacology, University of Pittsburgh School of Medicine, E 1340 Biomedical Science Tower, Pittsburgh, PA 15261. E-mail: flnst2@pitt.edu. DOI:10.1523/JNEUROSCI.4694-07.2008

Copyright $\odot 2008$ Society for Neuroscience $\quad$ 0270-6474/08/281977-11\$15.00/0 ness and pain. They consist of myelinated $\mathrm{A} \delta$-fibers and unmyelinated C-fibers, which terminate in the urothelium, suburothelial space and the muscle layers of the bladder (Gabella and Davis, 1998) and are activated by mechanical or chemical stimuli. Under normal conditions in conscious animals micturition is initiated by $\mathrm{A} \delta$-afferents. However, in pathological conditions and in anesthetized rats C-fibers are also involved (de Groat and Yoshimura, 2006).

The urothelium, a specialized epithelial tissue lining the urinary tract, is thought to play a role in bladder sensory mechanisms because it exhibits neuronal-like properties including the expression of various receptors (muscarinic, nicotinic, purinergic, transient receptor potential) and the ability to release various neurotransmitters (ACh, ATP, NO) that can influence the excitability of nearby afferent nerves (Birder and de Groat, 2007). $M_{1}$ to $\mathrm{M}_{5} \mathrm{mAChR}$ subtypes are expressed in the urothelium of different species (Giglio et al., 2005; Mansfield et al., 2005; Mukerji et al., 2006; Tyagi et al., 2006; Zarghooni et al., 2007; Kullmann et al., 2008). Activation of urothelial mAChRs releases a diffusible factor which inhibits carbachol induced smooth muscle contractions in pig (Hawthorn et al., 2000) or human (Chaiyaprasithi et al., 2003) bladder strips. In rat bladder tissue focal application of carbachol induces $\mathrm{Ca}^{2+}$ waves that originate in the urothelium and suburothelium and propagate into the muscle layer (Kanai et al., 2007).

Given the increasing evidence that the urothelium has neuronal-like properties that can affect sensory nerves and in 
turn influence bladder function, this study investigated the role of mAChRs located near the luminal surface of the bladder (i.e., urothelium and afferent nerves) in reflex voiding in rats by examining the effects of intravesical administration of a mAChR agonist and antagonist. The results indicate that activation of $\mathrm{mAChR}$ has both excitatory and inhibitory effects on voiding, which are mediated by $\mathrm{C}$-fiber afferents and involve ATP and NO release, presumably from the urothelium.

Parts of this paper have been published previously in abstract form (de Groat et al., 2004).

\section{Materials and Methods}

Experimental animals. Experiments were performed in adult female rats (Harlan, Indianapolis, IN; 200-250 g) whose care and handling was in accordance with the University of Pittsburgh Institutional Animal Care and Use Committee. One group of animals ( $n=11$ rats) was pretreated with capsaicin $(125 \mathrm{mg} / \mathrm{kg}$, s.c., dissolved in $10 \%$ ethanol, $10 \%$ Tween 80 and $80 \%$ physiological saline) to desensitize C-fiber afferent neurons. Capsaicin was administered under isoflurane anesthesia in three injections, divided in 25,50 , and $50 \mathrm{mg} / \mathrm{kg}$ doses over a $2 \mathrm{~d}$ period (at $\sim 12 \mathrm{~h}$ intervals), and the experiments were performed $4 \mathrm{~d}$ after the last injection. Another group of rats $(n=3)$ was treated with the capsaicin vehicle. The efficiency of capsaicin treatment was evaluated in each rat just before the experiment using an eye wipe test (Cheng et al., 1993), in which a few drops of $100 \mu \mathrm{M}$ capsaicin were placed in the eye and the number of defensive forelimb movements was observed. No defensive forelimb movements were noted in capsaicin treated rats whereas $>20$ movements $/ 2 \mathrm{~min}$ were noted in vehicle-treated rats. On visual inspection, the bladders from the capsaicin pretreated rats were larger than those of the untreated rats and had no signs of infection.

Continuous infusion cystometry. Rats were anesthetized with urethane $(1.2 \mathrm{~g} / \mathrm{kg}$, s.c.; Sigma, St. Louis, MO). Under supplemental isoflurane anesthesia, the jugular vein was exposed and a polyethylene (PE-10) catheter was inserted for intravenous drug delivery. The urinary bladder was exposed via a midline abdominal incision and a flared PE-50 catheter was inserted through the bladder dome and secured with a silk tie. The catheter was connected via a three-way connector to a pump for saline infusion and to a pressure transducer for bladder pressure recording. Voiding responses were elicited by continuously infusing saline $(0.9 \%$ $\mathrm{NaCl})$ at a rate of $0.04 \mathrm{ml} / \mathrm{min}$ at room temperature $\left(\sim 22^{\circ} \mathrm{C}\right)$.

$C M G$ data recording and analysis. Data were recorded for off-line analysis using Windaq data acquisition software (DATAQ Instruments, Akron, $\mathrm{OH}$ ) and analysis was performed using Excel (Microsoft, Redmond, WA), Origin version 7 (OriginLab, Northampton, MA), and Prism 4 (GraphPad Software, San Diego, CA). The continuous infusion cystometry $(\mathrm{CMG})$ parameters analyzed (see Fig. $1 A$ ) were intercontraction interval (ICI; defined as the time between two voiding episodes), amplitude of contractions (A; defined as the difference between bladder pressure at the peak of the contraction minus baseline bladder pressure), pressure threshold (PTh; defined as the bladder pressure necessary to evoke a voiding contraction), and baseline bladder pressure (BP; defined as the lowest bladder pressure just after voiding). Each of these parameters relates to a specific component of the reflex voiding (i.e., afferents, efferents, muscle). It is assumed that changes in ICI and PTh relate primarily to changes in the activity of the afferent nerves and/or changes in the afferent processing in the CNS (Yu and de Groat, 1999). Changes in $\mathrm{BP}$ reflect primarily changes in the bladder smooth muscle properties, whereas changes in contraction amplitude relate to changes in the activity of the efferent parasympathetic nerves and/or the contraction properties of the smooth muscle (Yu and de Groat, 1999). Control CMGs were performed for a period of 1.5-2 h before any drug application. Drugs used in this study were delivered intravesically or intravenously. For intravesical administration, drugs were dissolved in saline to a final concentration and applied for 30-60 min; washout periods lasted from 45-120 min or until a stable ICI was achieved. Antagonists were instilled for a period of 20-30 min before the agonist. For intravenous administration, drugs were dissolved in saline at desired dose and administered in small volumes $(100-200 \mu \mathrm{l})$ followed by $100 \mu \mathrm{l}$ of saline to flush the catheter. Intravenous injection of saline (100-300 $\mu \mathrm{l})$ did not alter CMG parameters ( $n=2$ rats). For each parameter (ICI, A, BP, PTh), at least four measurements were averaged during the control period just before drug application. For intravesical drug administration measurements of each parameter were averaged for the entire period the drug was infused (30-60 min). For intravenous drug administration parameters were averaged for periods specified in the text. A change in a CMG parameter was considered a drug effect if the change was at least two times greater than the SD of that parameter in control conditions. Data are reported as percentage changes relative to control which was set to $100 \%$.

Control experiments for the stability of CMG parameters were performed by infusing saline (at $0.04 \mathrm{ml} / \mathrm{min}$ ) for $8-10 \mathrm{~h}$. The ICI was stable during the course of the second to the eighth hour of recordings $(n=7$ rats) (see Fig. $1 B$ ). Data included in this study were typically collected during hours 2-6 after the start of CMGs.

Drugs used in this study include (1) nonselective muscarinic receptor agonists, oxotremorine methiodide (OxoM; 1-160 $\mu \mathrm{M}$ intravesical administration and $0.01-5 \mu \mathrm{g} / \mathrm{kg}$, i.v. administration) and oxotremorine sesquifumarate salt (OxoS; $10 \mu \mathrm{M}$, in vitro testing; Sigma); (2) nonselective muscarinic receptor antagonist, atropine methyl nitrate (AMN; 1-100 $\mu \mathrm{M}$ intravesical administration and $0.1-2 \mathrm{mg} / \mathrm{kg}$ i.v. administration; Sigma); (3) nonselective purinergic receptor antagonist 4-[[4formyl-5-hydroxy-6-methyl-3-[(phosphonooxy)methyl]-2-pyridinyl] azo]-1,3-benzenedisulfonic acid tetrasodium salt (PPADS; 0.1-1 mм intravesical administration; Sigma); and (4) nonselective inhibitor of nitric oxide (NO) synthase $N_{\omega}$-nitro-L-arginine methyl ester hydrochloride (L-NAME; 5, $25 \mathrm{mg} / \mathrm{kg}$, i.v. administration; Sigma)

Rat urothelial cell cultures were prepared as described previously (Birder et al., 1998). Female rats (200-250 g) were killed with $100 \% \mathrm{CO}_{2}$, the bladder was removed and placed in cold minimal essential medium (MEM; Invitrogen, Carlsbad, CA) supplemented with HEPES (2.5 g/l; Sigma) and containing penicillin/streptomycin/fungizone (PSF; $1 \%$; Sigma). The bladder was cut open to expose the urothelium, and incubated in dispase $(2.5 \mathrm{mg} / \mathrm{ml}$, Worthington Biochemical, Lakewood, NJ) overnight at $4^{\circ} \mathrm{C}$. Urothelial cells were gently scraped from the underlying tissue, placed in trypsin $\left(0.25 \% \mathrm{w} / \mathrm{v}\right.$; Sigma) for $10-15 \mathrm{~min}$ at $37^{\circ} \mathrm{C}$ and dissociated by trituration. Cells were suspended in MEM containing $10 \%$ fetal bovine serum (FBS; Invitrogen) and centrifuged at $416 \mathrm{~g}$ for 10 min. The supernatant was removed and cells were suspended in keratinocyte media (Invitrogen) with 1\% PSF, centrifuged again, and resuspended in fresh media. Cells were plated on collagen coated glass coverslips at densities of $50-125 \times 10^{4}$ cells $/ \mathrm{ml}$. Media was added after $4 \mathrm{~h}$ of incubation at $37^{\circ} \mathrm{C}$ and changed every other day. Cells were used $48-96 \mathrm{~h}$ after dissociation.

ATP release from cultured urothelial cells was performed as described previously (Birder et al., 2002). Coverslips containing urothelial cells were superfused with oxygenated Krebs [containing (in mM) $4.8 \mathrm{KCl}, 120$ $\mathrm{NaCl}, 1.1 \mathrm{MgCl}_{2}, 2.0 \mathrm{CaCl}_{2}, 11$ glucose, and 10 HEPES, $\left.\mathrm{pH} 7.4 ; 25^{\circ} \mathrm{C}\right]$ at a flow rate of $1 \mathrm{ml} / \mathrm{min}$. Drugs were bath applied via the perfusion system. Perfusate $(100 \mu \mathrm{l})$ was collected every 30 s before and after agonist stimulation and ATP levels were quantified using the luciferin-luciferase reagent (100 $\mu$; Adenosine Triphosphate Assay Kit, Sigma). Bioluminescence was measured using a luminometer (TD-20/20; Turner Biosystems, Sunnyvale, CA) whose detection limit was $\sim 5 \mathrm{fmol} \mathrm{ATP/}$ sample. Data were normalized by comparison to the peak ATP release induced by the calcium ionophore, ionomycin ( $5 \mu \mathrm{M}$; Sigma) used as a control at the end of each experiment. In these experiments, OxoS was used instead of OxoM because OxoM interfered with the assay. Pooled data are from a minimum of three cultures. Data analysis was performed using Excel (Microsoft) and Prism 4 (GraphPad Software).

Statistical analysis. Statistical significance was tested using paired, unpaired $t$ test, and ANOVA between groups followed by Newman-Keuls multiple-comparison test, (significance set at $p<0.05$ ) using Prism 4 (GraphPad Software). Data are presented throughout the text as mean \pm SEM.

\section{Results}

To determine whether in vivo activation of $\mathrm{mAChRs}$ located near the bladder lumen (i.e., urothelium and/or suburothelial afferent nerves) (Kullmann et al., 2008), affects voiding function, CMG 
A

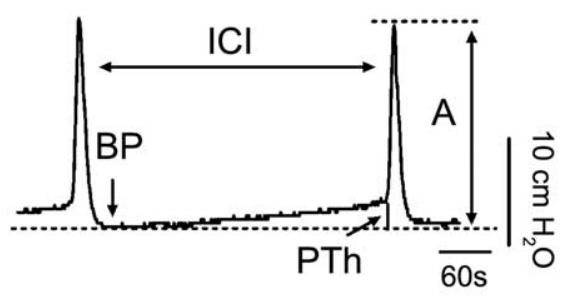

C

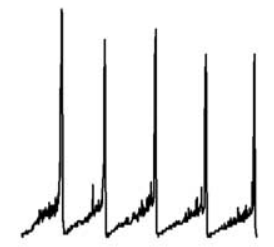

control

$|C|=447 \mathrm{~s}$

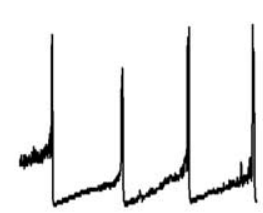

OxoM $5 \mu \mathrm{M}$

$\mathrm{ICl}=640 \mathrm{~s}$
B
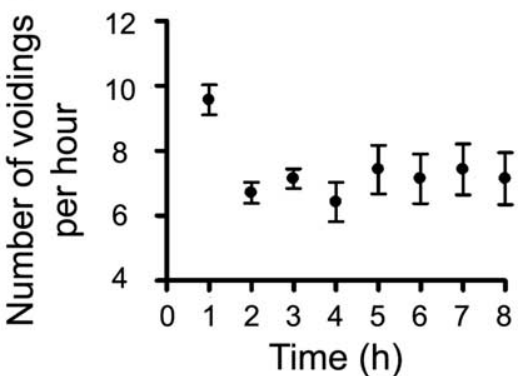

ICI by $38.6 \pm 6.4 \% ; n=8$ rats; paired $t$ test $p<0.05$ ) (Fig. 1C). Small amplitude nonvoiding contractions during bladder filling were also observed in the presence of OxoM at low and high concentrations (Fig. 1C) (data not quantified). To avoid prolonged instillation of OxoM into the bladder that may lead to penetration of OxoM into the bladder wall, concentration response curves were constructed in two groups of rats using two to three consecutive applications of increasing concentrations of OxoM, each lasting for $\sim 30-45$ min. In one group of rats, low concentrations of OxoM, 1 and $5 \mu \mathrm{M}$, increased ICI by $26.9 \pm 9.9 \%$ and by $32.1 \pm 9.6 \%$, respectively, $(n=9$ rats) (Fig. $1 D)$ without affecting other CMG parameters. Therefore, for further experiments, $5 \mu \mathrm{M}$ OxoM was used to elicit a consistent inhibitory effect and is referred to as "low" concentration. In another group of rats, high concentrations of OxoM, 20, 40 and $80 \mu \mathrm{M}$, were tested consecutively ( $n=9$ rats) (Fig. $1 D)$. OxoM at $20 \mu \mathrm{M}$ had mixed effects, producing inhibition or excitation. OxoM at 40 and $80 \mu \mathrm{M}$ produced consistent excitation, decreasing the ICI by $38.2 \pm 3.7 \%$ and $40.5 \pm 6.7 \%$, respectively ( $n=9$ rats), without any significant changes in other CMG parameters. Because the effects of 40 and $80 \mu \mathrm{M}$ OxoM on ICI were not different, the data obtained using 40 or $80 \mu \mathrm{M}$ OxoM were combined and designated as responses elicited by "high" concentrations of OxoM.

Neither low ( $5 \mu \mathrm{M}, n=12$ rats) nor high ( 40 or $80 \mu \mathrm{M}, n=18$ rats) concentrations of OxoM had a significant effect on the amplitude of contractions, PTh, or BP (Fig. 1E, Table 1).

\section{Effects of intravesical and intravenous administration of AMN}

The possibility that lumenal muscarinic receptors are tonically active and modulate

was performed in urethane anesthetized rats before and after intravesical administration of the mAChR agonist and antagonist, OxoM and AMN, respectively. These agents were selected because they have a reduced ability to pass through the urothelial barrier into the bladder wall because of their quaternary structure and their hydrophilic properties and therefore are less likely to activate mAChRs located in the bladder smooth muscle.

\section{Inhibitory and excitatory effects of intravesical OxoM}

Intravesical application of OxoM $(1-80 \mu \mathrm{M})$ had both inhibitory and excitatory effects on voiding functions depending on the concentration (Fig. 1C,D). Low concentrations $(1-5 \mu \mathrm{M})$ elicited predominantly inhibitory effects (i.e., decreasing voiding frequency), whereas high concentrations $(>20 \mu \mathrm{M})$ elicited predominantly excitatory effects (i.e., increasing voiding frequency). Both effects could be elicited in the same animal $(5 \mu \mathrm{M}$ OxoM increased ICI by $37.5 \pm 16.0 \%$, whereas $40 \mu \mathrm{M}$ OxoM decreased voiding function was tested by instilling AMN into the bladder. Intravesical administration of $1-100 \mu \mathrm{M}$ AMN had no significant effect on ICI, PTh, and BP (Fig. 2A, Table 2). At 5 and $50 \mu \mathrm{M}$, AMN slightly but not significantly decreased the amplitude of contractions, whereas at $100 \mu \mathrm{M}, \mathrm{AMN}$ significantly decreased the amplitude of the contractions (Fig. 2A, Table 2). The effects were long lasting and only partially reversed after washout (amplitude reduced to: $58.5 \pm 8.7 \%$ of control by AMN $100 \mu \mathrm{M}$ and to $67.7 \pm 8.9 \%$ of control after $57 \pm 22$ min of saline wash; $n=2$ rats). In some rats, after observing the effect of intravesical administration of AMN (100 $\mu$; i.e., the decrease in the contraction amplitude) and while maintaining the intravesical infusion of AMN $(100 \mu \mathrm{M}), \mathrm{AMN}$ was also administered intravenously $(0.1-2 \mathrm{mg} / \mathrm{kg}, n=4 \mathrm{rats})$ and voiding was monitored for another $30 \mathrm{~min}$. Even at the lowest dose $(0.1 \mathrm{mg} / \mathrm{kg}), \mathrm{AMN}$ intravenously produced an immediate decrease in amplitude, ICI, and PTh, similar to previous reports (Hegde et al., 1997; Ishiura et al., 2001; 
Takeda et al., 2002), lasting for 5-10 min, followed by a partial recovery of the amplitude, ICI and PTh (Fig. 2 B, C, Table 2 ). These data suggested that mAChRs located on the bladder sensory pathways are not tonically active. They also indicated that penetration of $\mathrm{AMN}$ through the urothelium is poor and that the sites of action of AMN are different depending on the route of administration. Because AMN does not readily cross the blood-brain barrier or the urothelial barrier, when delivered intravenously it most likely blocks mAChRs located in the smooth muscle, whereas when delivered intravesically it does not act directly on the smooth muscle but it blocks mAChRs located within or near the urothelium.

\section{Inhibitory effects of intravesical administration of OxoM}

Intravesical infusion of low concentrations of OxoM ( 1 and $5 \mu \mathrm{M}$ ) decreased the frequency of voiding in $71 \%$ of the rats (12 of 17) (ICI increased to $134.3 \pm 5.3 \%$ of control; $n=12$ rats (Fig. $3 A i, B i, C$, Table 1 ). In four rats, OxoM $(5 \mu \mathrm{M})$ had an excitatory effect, reducing ICI to $58.4 \pm 9.7 \%$ of control, whereas in one rat OxoM ( 1 and $5 \mu \mathrm{M})$ had no effect (ICI was $92.4 \%$ and $93.9 \%$ of control, respectively); however, subsequent applications of OxoM $(40 \mu \mathrm{M})$ after a wash of $>30 \mathrm{~min}$ in this rat produced excitation (decreasing ICI by $\sim 50 \%$ ). OxoM $5 \mu \mathrm{M}$ had no significant effect on other CMG parameters (A, PT, BP) (Fig. $1 E)$. Continuous intravesical infusion of saline did not elicit a significant change in ICI (Fig. 3, compare Bi, Bii) $(n=12$ rats for OxoM $5 \mu \mathrm{M}$ and $n=7$ rats for saline; unpaired $t$ test, $p<0.05$ ), thus indicating that a spontaneous change in voiding was unlikely to account for the OxoM inhibitory effects. The inhibitory effects persisted for the period of OxoM infusion, in some cases $>90 \mathrm{~min}$, and were partially reversed after washout (from $129.2 \pm 18.2 \%$ to $113.3 \pm 17.1 \%$ of control after a washout time of $\sim 80 \mathrm{~min}, n=5$ rats, paired $t$ test $p>0.05$ ) (Fig. 3 Aii). However, the inhibition was not repeatable in the same animal; usually a second application of $5 \mu \mathrm{M}$ OxoM elicited an excitatory effect (ICI decreased to $66.2 \pm 3.6 \%$ of control, $n=5$ rats) (Fig. 3Aii). AMN ( $5 \mu \mathrm{M})$ administered after the inhibitory effect of OxoM was established ( $\sim 30 \mathrm{~min})$ significantly reduced the inhibitory effects (from $128.1 \pm 4.0 \%$ to $111.7 \pm 7.1 \%$ of control; $n=10$ rats; paired $t$ test $p<0.05$ ) (Fig. 3Aiii,C).

\section{Excitatory effects of intravesical administration of OxoM}

High concentrations of OxoM ( 40 or $80 \mu \mathrm{M}$ ) produced consistent excitation (i.e., increased voiding frequency) in $90 \%$ of the rats $(n=18$ of 20$)$, reducing the ICI to $57.8 \pm 4.1 \%$ of control (Fig. $4 A i$, Table 1 ). In one rat, OxoM $80 \mu \mathrm{M}$ had no effect (ICI was $98.6 \%$ of control) and in another rat OxoM had an inhibitory effect increasing ICI to $154 \%$ of control. Subsequent application of $160 \mu \mathrm{M}$ OxoM in this rat produced excitation, decreasing ICI by $35 \%$. The excitatory effects were reversible after washout, reproducible in the same animal $(n=5$ rats) (Fig. 4 Aii) and blocked by intravesical administration of $\operatorname{AMN}(5 \mu \mathrm{M} ; n=5$ rats $)$ (Fig. 4Aiii).

A plot of the time course of the changes in ICI before and after OxoM instillation revealed that the excitatory effects were time dependent, displaying two phases (Fig. $4 B$ ). The first phase consisted of a marked reduction in the ICI without any change in other parameters and was evident after the first or second voiding after OxoM application. The second phase consisted of a partial recovery (lengthening) of the ICI without detectable changes in other parameters in the majority of rats (78\% of rats; 14 of 18 ) (Fig. $4 \mathrm{Bi}$ ). In a small population of rats $22 \%$ ( 4 of 18 ) the second phase was accompanied by a slight, but not significant, increase in PTh (Fig. 4 Bii) (to $153.9 \pm 34.5 \%$ of control, $n=4, p>0.05$ paired $t$ test), and in two of these rats also by an increase in baseline pressure (Fig. 4 Biii) (to $272.7 \pm 23.1 \%$ and to $158.5 \pm$ $5.3 \%$ of control, respectively). The changes in ICI caused by high concentrations of OxoM were significantly different from changes in ICI caused by saline $(n=18$ rats treated with OxoM 
Table 2. Effects of intravesical and intravenous administration of AMN on CMG parameters

\begin{tabular}{lcc}
\hline & Control & AMN \\
\hline AMN $5 \mu \mathrm{M}(n=7$ rats $)$ & & \\
ICl $(\mathrm{s})$ & $536.6 \pm 79.9$ & $602.8 \pm 76.8$ \\
Amplitude $\left(\mathrm{cmH}_{2} 0\right)$ & $31.2 \pm 1.9$ & $27.1 \pm 1.7$ \\
PTh $\left(\mathrm{cmH}_{2} 0\right)$ & $7.2 \pm 1.4$ & $8.0 \pm 1.9$ \\
BP $\left(\mathrm{cmH}_{2} 0\right)$ & $4.5 \pm 0.5$ & $4.5 \pm 0.7$ \\
AMN $100 \mu \mathrm{M}(n=4$ rats $)$ & & \\
ICl $(\mathrm{s})$ & $411.1 \pm 54.1$ & $395.8 \pm 54.9$ \\
Amplitude $\left(\mathrm{cmH}_{2} 0\right)$ & $32.8 \pm 3.2$ & $22.6 \pm 2.4^{*}$ \\
PTh $\left(\mathrm{cmH}_{2} 0\right)$ & $8.6 \pm 2.1$ & $8.4 \pm 1.3$ \\
BP $\left(\mathrm{cmH}_{2} 0\right)$ & $5.0 \pm 0.6$ & $5.2 \pm 0.7$ \\
Intravenous AMN $(0.1-2 \mathrm{mg} / \mathrm{kg})$ after intravesical AMN $(n=4$ rats; control is $100 \mu \mathrm{m}$ intravesical AMN \\
& & $10 \mathrm{~min} />10 \mathrm{~min}$ \\
ICl $(\mathrm{s})$ & $356.9 \pm 69.8$ & $185.0 \pm 50.6^{*} / 225.1 \pm 44.0$ \\
Amplitude $\left(\mathrm{cmH}_{2} 0\right)$ & $23.7 \pm 3.1$ & $14.1 \pm 1.7^{*} / 16.7 \pm 1.6$ \\
PTh $\left(\mathrm{cmH}_{2} 0\right)$ & $5.8 \pm 1.5$ & $2.8 \pm 0.4 / 3.3 \pm 0.92$ \\
BP $\left(\mathrm{cmH}_{2} 0\right)$ & $5.1 \pm 0.7$ & $6.1 \pm 0.8 / 6.0 \pm 0.8$ \\
\hline
\end{tabular}

For AMN intravenous, data were averaged in the first $10 \mathrm{~min}$ and in the next $10-30 \mathrm{~min}(>10 \mathrm{~min})$ after delivery. Voiding was monitored in these rats for an average of $31.8 \pm 7.5 \mathrm{~min}$ after intravenous delivery of AMN. Asterisks indicate statistically significant differences $(p<0.05)$ from control tested with paired $t$ test.

A

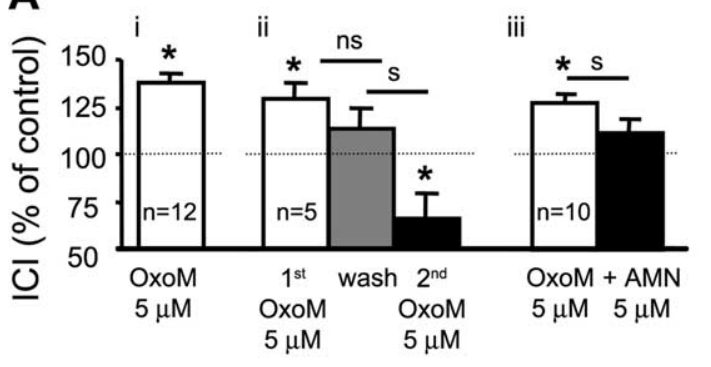

B

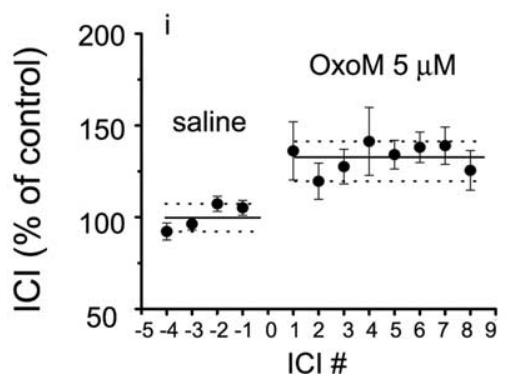

C

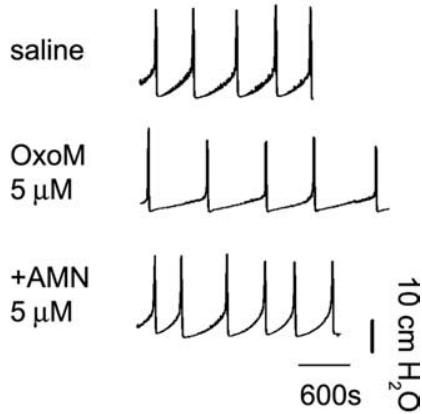

Figure 3. Inhibitory effects of intravesical administration of $0 \times 0 M . A i$, Low concentrations of $0 \times 0 M(5 \mu M)$ increased the ICl (summary from $n=12$ rats). Aii, The inhibitory effects on ICI (white bars) were partially reversible after $\sim 80$ min wash (gray bars), and a second application produced excitation (black bar; summary from $n=5$ rats). Aiii, The effects on ICl (white bars) were significantly reduced by intravesical administration of AMN ( $5 \mu \mathrm{m}$; black bars; summary from $n=10$ rats; example in $C$ ). Asterisks indicate significant changes $(p<0.05)$ from control, tested with paired $t$ test. Dotted lines represent control set to $100 \%$. s, Significant difference; ns, no significant difference (tested with paired $t$ test between the groups indicated). Bi, Time course of the inhibitory effects of $0 x 0 M(n=12$ rats). ICI number (\#) 0 indicates when $0 x 0 M$ was applied. A negative ICI \# refers to ICls before drug application and a positive ICI \# refers to ICls after drug application. The thick line represents mean and dotted lines represent confidence interval (5,95\%). Bii, Similar data from control experiments in which saline was instilled instead of 0xoM ( $n=7$ rats). C, Inhibitory effect of $0 x 0 \mathrm{M}(5 \mu \mathrm{M})$ on ICl, which is reversed by intravesical administration of AMN $(5 \mu \mathrm{M})$.

$40-80 \mu \mathrm{M}$ and $n=7$ rats treated with saline; unpaired $t$ test, $p<$ 0.05) (compare Figs. 3Bii, 4C).

\section{Effects of intravenous administration of OxoM}

To demonstrate that the effects of intravesical OxoM application were caused by activation of $\mathrm{mAChRs}$ located in urothelium and/or afferent nerves rather than activation of receptors located in the smooth muscle, OxoM was administered intravenously. Systemic effects of OxoM intravenously including increased salivation were observed starting at very low doses (effects not quantified). Because OxoM does not readily cross the bloodbrain barrier, when delivered intravenously it likely activates receptors in the periphery. In preliminary experiments, dose-response curves for intravenous OxoM (0.01-5 $\mu \mathrm{g} / \mathrm{kg}$, i.v., $n=5$ rats) (Fig. $5 A$ ) were constructed by administering increasing doses every 30-45 min. Doses that produced significant effects $(4-5 \mu \mathrm{g} /$ $\mathrm{kg}$ ) on CMG parameters were chosen for further testing. The effects of intravenous OxoM on CMG parameters were short lasting, returning to control within 10-30 min (depending on the dose). For this reason data were summarized for a period of 10-20 min immediately after drug application. In contrast to intravesical administration, intravenous administration of OxoM had no significant effect on the ICI and PTh (Fig. $5 C$, white bars) $(n=5$ rats paired $t$ test $p>0.05)$, but produced an acute increase in the intravesical pressure (IVP; $\Delta \mathrm{IVP}=10.4 \pm 2.0 \mathrm{cmH}_{2} \mathrm{O}$ after OxoM $4 \mu \mathrm{g} / \mathrm{kg}$, i.v.; $n=5$ rats; paired $t$ test $p<0.05$ ) (Fig. 5A,Bi) and a significant increase in A and BP (Fig. $5 C$, white bars) (paired $t$ test $p<0.05$ ). In experiments with multiple OxoM applications, the effects of OxoM were not prevented by intravesical administration of AMN $(5 \mu \mathrm{M}$; 50-60 min before administration of the next dose of OxoM) (Fig. $5 A, B i i, C$, black bars $)\left(\Delta \mathrm{IVP}=13.3 \pm 2.9 \mathrm{cmH}_{2} \mathrm{O}\right.$ after OxoM $5 \mu \mathrm{g} / \mathrm{kg}$, i.v.; $n=5$ rats; paired $t$ test $p>0.05)$. These results indicate that the effects on CMG parameters of intravesical and i.v. OxoM were different, consistent with activation of $\mathrm{mAChRs}$ located at different sites in the bladder.

\section{Capsaicin pretreatment prevents the effects of intravesical \\ OxoM administration}

As intravesical OxoM produced changes in voiding frequency, likely reflecting an action on afferent nerves (Lecci et al., 2001), we next investigated what types of afferent nerves ( $\mathrm{C}$ or $\mathrm{A} \delta$ type) mediate these effects. Previous studies showed that C-fiber afferents play a significant role in voiding in rats, especially under urethane anesthesia (Cheng et al., 1993). To assess whether the effects of intravesical OxoM involve activation of C-fiber afferents, rats were pretreated with capsaicin $4 \mathrm{~d}$ before assessing CMG parameters to desensitize the C-fibers. Similar to previous findings (Yu and de Groat, 1999), these rats had longer ICIs and higher PTh than untreated or vehicle-treated rats (Fig. $6 A, B)$. In vehicle-treated rats $(n=3$ rats), which had CMG parameters (ICI, PTh, BP, A) comparable 


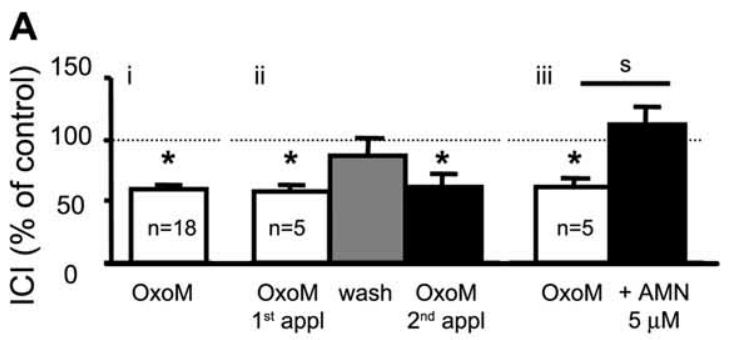

B
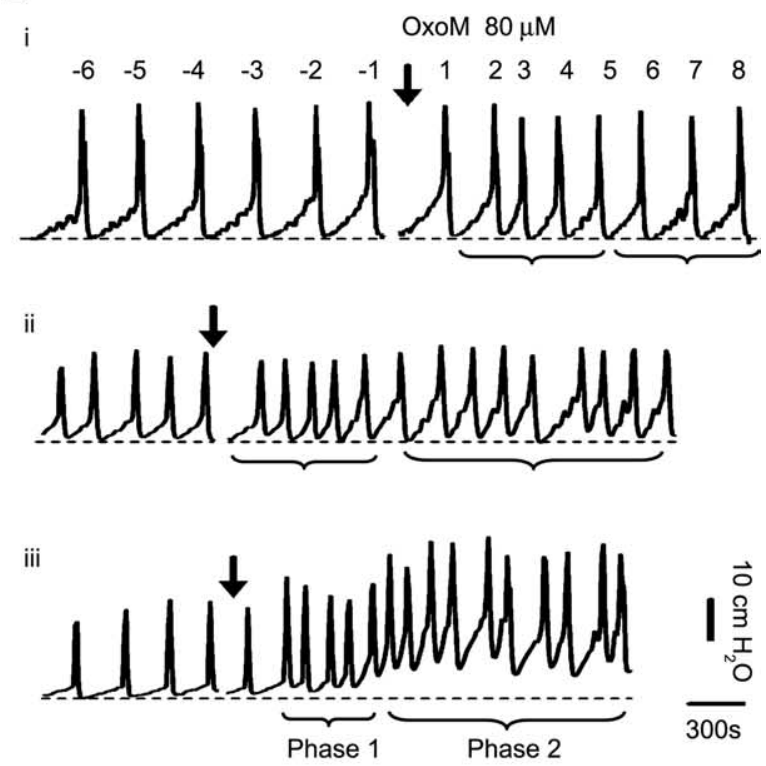

C

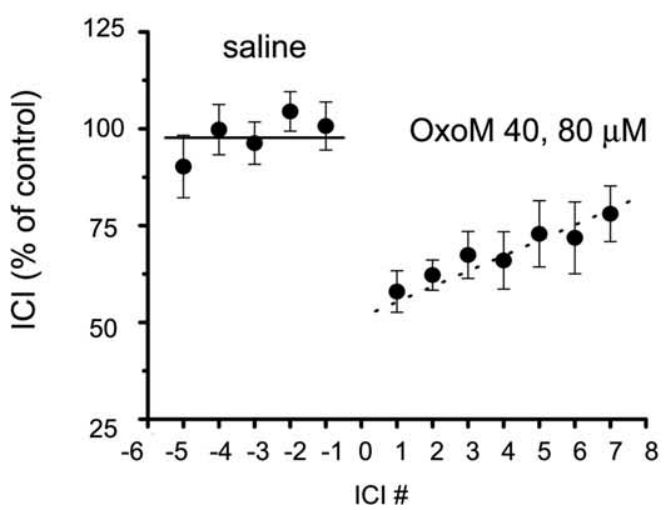

Figure 4. Excitatory effects of intravesical administration of 0 xoM. Ai, High concentrations of OxoM $(40,80 \mu \mathrm{m})$ reduced ICI (summary from $n=18$ rats). Aii, The effects of $0 x 0 M(40,80 \mu \mathrm{m})$ on ICI (white bars) were reversible after washout (gray bars) and repeatable (black bar); summary from $n=$ 5 rats. Aiii, The effects of 0 xoM $(80 \mu \mathrm{m})$ were blocked by intravesical administration of AMN ( $5 \mu \mathrm{m}$; summary from $n=5$ rats). Dotted lines represent control set to $100 \%$. Asterisks indicate significant changes $(p<0.05)$ from control, tested with paired $t$ test. $s$, Significant differences tested with paired $t$ test between the groups indicated in figure. $\boldsymbol{B}$, Time dependence of the excitatory effects of intravesical OxoM. Examples from three rats. Biillustrates the most common pattern (found in $78 \%$ of rats): initially the ICI becomes shorter (phase 1), then ICI lengthens (phase 2), but it is still shorter than control, without any changes in other CMG parameters. Numbers on top of voiding contractions represent the number of the ICI before (negative values) and after (positive values) 0 xoM application, which are used for quantification in C. Bii illustrates an example in which PTh increases slightly during phase 2. Biii illustrates an example in which BP increases during phase 2. Dotted lines indicate baseline pressure before $0 \times 0 M$ application. Arrows in each panel indicate the time when $0 \times 0 M$ infusion was started. C, Quantification of the time dependence of the excitatory effects of $0 x 0 \mathrm{M}(40,80 \mu \mathrm{m}$; summary from $n=18$ animals). ICl number (\#) 0 indicates when 0 xoM was applied. The line shows average of control data and dotted line represents linear fitting of the data during $0 x 0 \mathrm{M}$ application. with those of untreated rats, OxoM $(40 \mu \mathrm{M})$ had similar excitatory effects; thus, data from vehicle-treated and untreated rats were combined and compared with data from capsaicin pretreated rats.

In the capsaicin pretreated rats intravesical administration of OxoM (5-160 $\mu \mathrm{M})$ did not significantly change the voiding frequency, A and BP, but increased significantly PTh (Fig. 6C,D). This increase was associated with a change in the slope of the filling curve (Fig. 6C), suggesting that OxoM may have reached the muscarinic receptors in the detrusor muscle. This may have occurred as a result of an increased permeability of the urothelium. It is known that the absorption of intravesical fluids is increased in over-distended bladders (Sugaya et al., 1997) and bladders of capsaicin pretreated rats are over-distended (Santicioli et al., 1985), therefore making it possible for drugs to penetrate the urothelial barrier during infusion. However, there was no increase in $\mathrm{BP}$ as expected from a direct action of OxoM on the muscle (Fig. 6C) (OxoM, i.v.), therefore the amount of OxoM that may have reached the bladder smooth muscle was likely very small. Administration of OxoM intravenously $(0.01-2 \mu \mathrm{g} / \mathrm{kg}$ ) elicited effects similar to those observed in untreated rats (i.e., acute increase in intravesical pressure without affecting the voiding frequency; $\Delta \mathrm{IVP}=8.8 \pm 1.2 \mathrm{cmH}_{2} \mathrm{O} ; n=3$ rats; paired $t$ test $p<0.05$ ) (Fig. $6 E$ ) and these effects were not prevented by intravesical administration of $\mathrm{AMN}(5 \mu \mathrm{M} ; \sim 50$ min preincubation; $\Delta \mathrm{IVP}=8.3 \pm 2.0 \mathrm{cmH}_{2} \mathrm{O} ; n=3$ rats; paired $t$ test $p<0.05$ ) (Fig. 6E).

The inhibitory effects of intravesical OxoM involve NO Previous studies have shown that $\mathrm{NO}$ can be released from the urothelium and nerves (Birder et al., 1998) and can affect voiding frequency (Pandita et al., 2000). NO donors can also affect bladder afferent neuron excitability by modulating $\mathrm{Ca}^{2+}$ channels (Yoshimura et al., 2001) and when administered intravesically NO donors can suppress bladder hyperactivity induced by cystitis (Ozawa et al., 1999). To test the involvement of NO in the observed OxoM effects, the NOS inhibitor L-NAME (Masuda et al., 2007) was administered before OxoM. L-NAME alone at $5 \mathrm{mg} / \mathrm{kg}$ and $25 \mathrm{mg} / \mathrm{kg}$ (i.v.) increased the ICI, PTh, A, and BP in a dosedependent manner ( $n=9,6$ rats in each group respectively) (Fig. $7 A$ ). These effects lasted for $>3-4 \mathrm{~h}$ and might be related to a block of NO mediated urethral smooth muscle relaxation and an increase in the urethral outlet resistance during micturition (Bennett et al., 1995; Masuda et al., 2007). Because $5 \mathrm{mg} / \mathrm{kg}$ L-NAME had fewer effects on CMG parameters (i.e., only the amplitude increased significantly from control; paired $t$ test $p<$ $0.05 ; n=9$ rats), this dose was chosen for further studies. OxoM was instilled intravesically $\sim 45-60$ min after L-NAME, when ICI was stable. Intravesical instillation of low concentrations of OxoM ( $5 \mu \mathrm{M})$ slightly, but not significantly, increased the ICI in $78 \%$ of rats ( 7 of 9 ; ICI increased to $111.4 \pm 7.3 \%$ of control, $n=$ 7 rats; paired $t$ test $p>0.05$ ) (Fig. $7 B, C$ ) with no changes in other CMG parameters. This inhibitory effect was significantly less than the inhibitory effect of OxoM in the untreated rats (where ICI increased to $134.3 \pm 5.3 \%$ of control; $n=12$ rats; unpaired $t$ test $p<0.05$ ) (compare with Fig. 3Bi). In the remaining $22 \%$ of rats ( 2 of 9 ) low concentrations of OxoM produced an excitatory effect, reducing the ICI to $66.3 \pm 2.0 \%$ of control without any changes in other CMG parameters. Instillation of high concentrations of OxoM $(40 \mu \mathrm{M})$ after L-NAME administration produced consistent excitation reducing the ICI to $72.8 \pm 7.4 \%$ of control ( $n=6$ rats; paired $t$ test $p<0.05$ ) (compare Figs. $4 C$, $7 D, E$ ) without any other changes in CMG parameters. L-NAME 


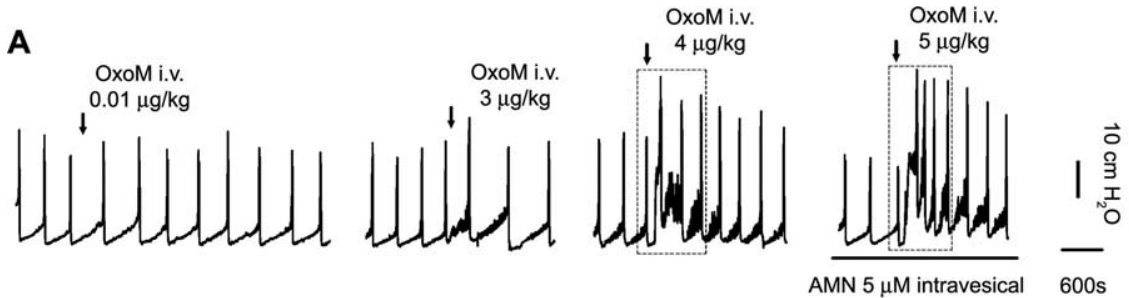

B
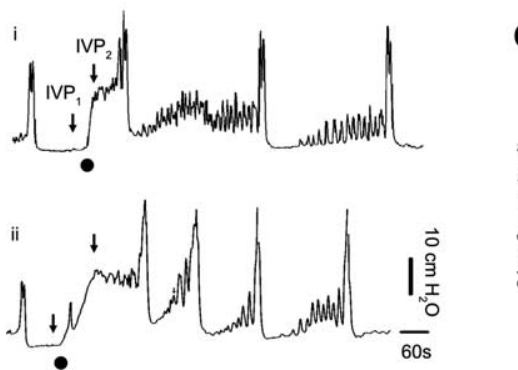

C

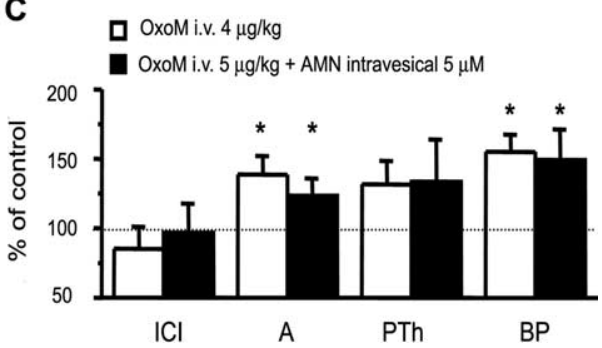

Figure 5. Effects of intravenous administration of $0 \times 0 \mathrm{M}$ on $\mathrm{CMG}$ parameters. $\boldsymbol{A}$, Effects of increasing doses of intravenous 0xoM on CMG parameters. The highest dose $(5 \mu \mathrm{g} / \mathrm{kg}$ ) was administered in the presence of intravesical AMN ( $5 \mu \mathrm{m}$ for $\sim 50 \mathrm{~min}$ before intravenous administration of $0 \times 0 M)$. Note that the effects of intravenous $0 x 0 M$ were not blocked by intravesical administration of AMN (5 $\mu \mathrm{M})$. Bi and Bii show enlargements of the dotted areas in $\boldsymbol{A}$ illustrating an acute increase in the IVP after administration of $0 \times 0 M$ (black circle). IVP was measured before $\left(I V P_{1}\right)$ and after $\left(I V P_{2}\right)$ intravenous 0 xoM delivery at the time points indicated by arrows. C, Quantification of the changes in CMG parameters produced by intravenous administration of $0 \times x_{0} M$ in the absence (white bars) and in the presence (black bars) of intravesical AMN ( $5 \mu \mathrm{m}$; summary from $n=5$ rats). Asterisks indicate statistically significant differences (paired $t$ test $p<0.05$ ) relative to control.

did not affect the time-dependency of the excitatory effects of OxoM (i.e., the two phases of the excitation) (Fig. 7D).

\section{The excitatory effects of OxoM are mediated in part by ATP} Previous studies have shown that bladder distention triggers ATP release from the urothelium (Ferguson et al., 1997; Kumar et al., 2004), which can then act on afferent nerves to increase their excitability (Cockayne et al., 2000; Vlaskovska et al., 2001; Burnstock, 2006). To test whether the excitatory effects of OxoM on ICI were mediated via purinergic mechanisms, OxoM (40-80 $\mu \mathrm{M})$ was administered in the presence of the nonselective purinergic antagonist PPADS $(0.1,0.2$, and $1 \mathrm{~mm}$, intravesically, in concentrations shown to significantly reduce the afferent nerve activity during bladder distension) (Vlaskovska et al., 2001). Regardless of the PPADS concentration, the excitatory effect of OxoM was attenuated (OxoM reduced ICI to $61.8 \pm 16.8 \%$ of control in the absence of PPADS and to $75.2 \pm 17.0 \%$ of control in the presence of PPADS, $n=13$ rats; paired $t$ test $p<0.05$ ) (Fig. $8 A, B)$. There was variation from rat to rat in the size of the effect (Fig. $8 \mathrm{~A}$ ), which was not correlated with the concentration of PPADS, suggesting that even the lower concentrations of PPADS were effective at blocking purinergic receptors. The two phases of the excitatory effect still occurred in the presence of PPADS (Fig. $8 B, C)$ and PPADS (0.1-1 mM) alone did not significantly alter CMG parameters $(n=13$ rats; paired $t$ test $p>0.05)$.

\section{Muscarinic agonists release ATP from cultured urothelial cells}

To determine whether activation of urothelial $\mathrm{mAChRs}$ results in ATP release, ATP was measured in perfusate of cultured urothelial cells. In these experiments OxoS was used because OxoM interfered with the ATP assay. The calcium ionophore ionomycin $(5 \mu \mathrm{M})$ was applied at the end of each experiment to elicit a maximal ATP release that was used to normalize data between coverslips with varying number of cells (Birder et al., 2003). OxoS (10 $\mu \mathrm{M}$, applied for $60-120 \mathrm{~s}$ ) evoked release of ATP that lasted for 1-6 min and was repeatable in the same preparation ( $n=5$ coverslips) (Fig. $8 D$ ) (first and second $\mathrm{OxoS}$ responses were $14.1 \pm 7.1 \%$ and $11.0 \pm 3.6 \%$ of the ionomycin response, respectively). Preincubation with AMN $(20 \mu \mathrm{M})$ reduced OxoSevoked ATP release by $60.9 \pm 9.7 \%(n=5$ coverslips) (Fig. 8 E). AMN alone did not have an effect on ATP levels (basal ATP levels, $6.6 \pm 0.7 \mathrm{fmol} / 100 \mu \mathrm{l} \mathrm{ATP}$, and in $20 \mu \mathrm{M}$ AMN, $8.7 \pm 0.9 \mathrm{fmol} / 100 \mu \mathrm{l} ; n=5$ coverslips; paired $t$ test $p>0.05)$.

\section{Discussion}

Intravesical instillation of the muscarinic agonist OxoM elicited inhibitory and excitatory effects on voiding frequency that were abolished by intravesical instillation of the muscarinic antagonist AMN or by pretreatment with capsaicin, indicating that they were dependent on C-afferent fiber activation. The inhibitory effects involved NO because L-NAME, a NOS synthesis inhibitor, blunted the inhibition. The excitatory effects were reduced by a purinergic receptor antagonist PPADS; and OxoS released ATP from cultured urothelial cells, suggesting that the excitation is partially mediated through ATP likely released from urothelium. I.v. administration of OxoM had different effects on bladder reflex activity and these effects were not blocked by AMN administered intravesically. These results suggest that in vivo activation of mAChRs located in bladder sensory pathways alters voiding frequency via multiple mechanisms likely involving urothelial derived factors that in turn alter the excitability of C-afferent nerves.

\section{Site of action of intravesical OxoM}

mAChRs are expressed throughout the bladder: in urothelium, myofibroblasts, afferent and efferent nerves and smooth muscle (Abrams et al., 2006). For several reasons, it is likely that the effects of OxoM administered intravesically were caused by activation of mAChRs located in the urothelium or just beneath the urothelium (afferent nerves, myofibroblasts), rather than a direct action on the bladder smooth muscle. First, OxoM and AMN have limited ability to cross the urothelial barrier because of their quaternary structure and hydrophilic properties. Our experiments indicated that this is indeed the case because (1) both OxoM and AMN delivered intravesically had different effects than when delivered intravenously (Figs. 2-5), and (2) AMN intravesically blocked the intravesical effects of OxoM, but did not alter the intravenous effects of OxoM (Figs. 3-5). Furthermore, to reach the smooth muscle, OxoM would have to pass through the lamina propria, a tissue rich in blood vessels and therefore likely to be taken up in the bloodstream to produce systemic effects such as increased salivation. However, systemic effects were absent after intravesical OxoM, but were observed after intravenous injection of OxoM even at low doses $(0.1 \mu \mathrm{g} /$ $\mathrm{kg}$ ) that had minimal effects on bladder activity. Second, intravesical OxoM altered the frequency of voiding without significantly changing the amplitude of contractions or basal bladder pressure (Figs. 1E, 3, 4). This is similar to the effects of agents such as capsaicin, known to act on afferent nerves (Lecci et al., 


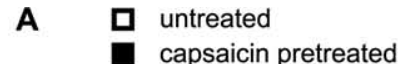
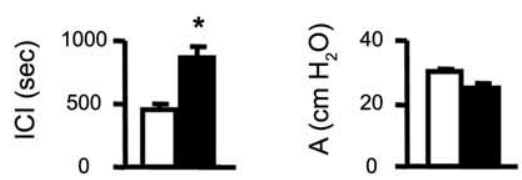

C

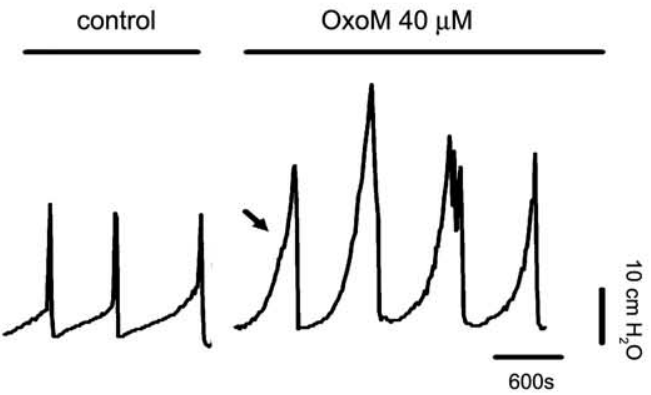

E

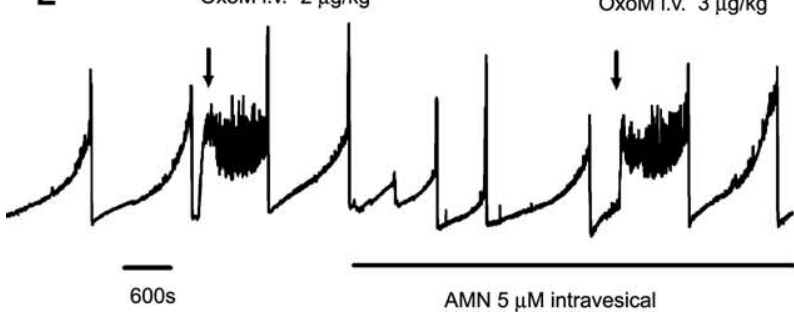

B

i untreated

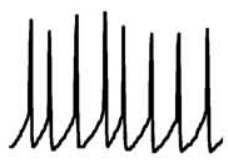

ii capsaicin pretreated

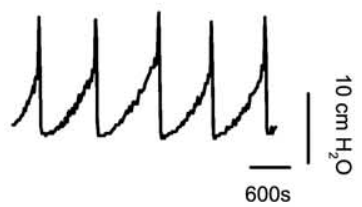

D

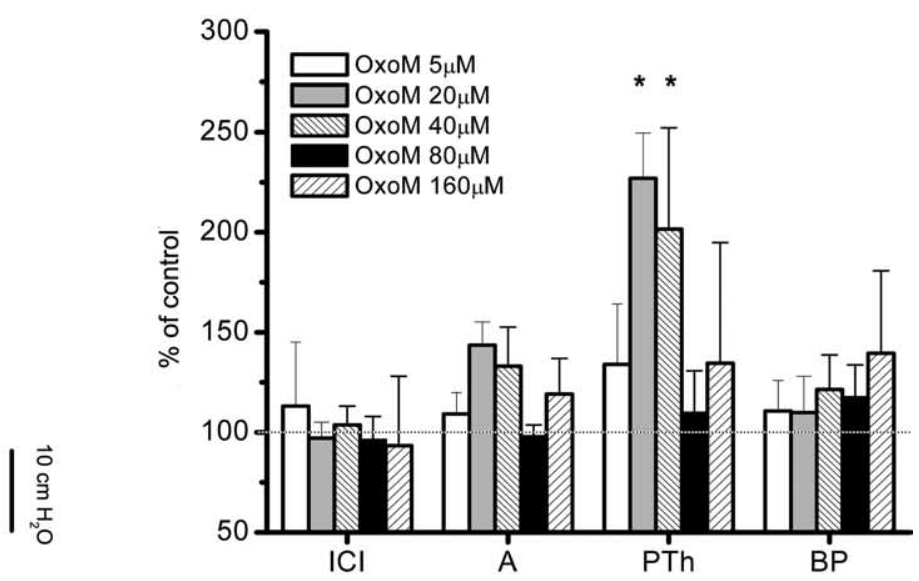

Figure 6. Effects of intravesical and intravenous administration of $0 \times 0 M$ in capsaicin pretreated rats. $A$, Comparison of $C M G$ parameters between untreated and capsaicin pretreated rats, before 0xoM application (summary from $n=21$ untreated rats and $n=14$ capsaicin pretreated rats). Asterisks indicate significant changes ( $p<0.05)$ from control, tested with paired $t$ test. $B$, CMG recordings from an untreated rat (Bi) and a capsaicin pretreated rat (Bii), illustrating the differences in ICI. Traces are on the same time scale for comparison. $\boldsymbol{C}$, Effects of intravesical 0 oxoM in a capsaicin pretreated rat. The arrow points to PTh. $D$, Intravesical administration of $0 \times$ xoM at increasing concentrations did not affect ICl, $A$, or BP, but increased PTh (summary from $n=5,3,9,7$, and 3 , animals for $0 \times 0 M 5,20,40,80$, and $160 \mu \mathrm{M}$, respectively). Dotted line represents control set to $100 \%$. Asterisks indicate significant changes $(p<0.05)$ from control, tested with paired $t$ test. $\boldsymbol{E}$, Effects of intravenous $0 x 0 M$ in a capsaicin pretreated rat in the absence and in the presence of intravesical AMN ( $5 \mu \mathrm{M}$ for $>50$ min before i.v. administration of $0 \times 0 \mathrm{M}$ ). Note that the effects of intravenous 0 xoM were not blocked by intravesical administration of AMN.

2001), indicating an action of OxoM on the afferent nerves. In contrast, OxoM delivered intravenously produced a marked increase in intravesical pressure and contraction amplitude with little effect on voiding frequency (Fig. 5), suggesting an action on the smooth muscle mAChRs. Third, systemic capsaicin pretreatment to desensitize C-fibers, abolished the intravesical effects of OxoM, but did not affect the intravenous effects (Fig. 6). Fourth, even low intravesical concentrations of OxoM (1 and $5 \mu \mathrm{M})$, that presumably only activated $\mathrm{mAChRs}$ on the lumenal surface of the urothelium, elicited changes in the ICI that were blocked by intravesical administration of AMN (5 $\mu \mathrm{M})$ (Fig. 3). Fifth, the effects of intravesical OxoM were rapid, occurring shortly after infusion (Fig. 4). This coupled with limited permeability of OxoM strongly argue that the effects were not caused by a direct action on the muscle. Sixth, OxoM did not significantly affect the amplitude of the contractions, suggesting that OxoM did not penetrate the urothelium to reach the parasympathetic efferent nerves. These nerves contain presynaptic $\mathrm{M}_{1}$ and $\mathrm{M}_{2} / \mathrm{M}_{4}$ $\mathrm{mAChRs}$ that modulate transmitter release (Somogyi and de Groat, 1992; Somogyi et al., 1994; Braverman et al., 1998; Zhou et al., 2002). These data provide strong evidence that intravesical OxoM activates mAChRs located in the bladder sensory pathways including urothelium and afferent nerves. The expression of $\mathrm{mAChRs}$ in the sensory pathways was shown with RT-PCR or immunohistochemistry (Giglio et al., 2005; Mansfield et al., 2005; Mukerji et al., 2006; Tyagi et al., 2006; Zarghooni et al., 2007), but this is the first demonstration that in vivo activation of these receptors elicits complex effects on bladder function.

\section{Inhibitory mechanisms}

Intravesical administration of low concentrations $(1,5 \mu \mathrm{M})$ of OxoM had a predominant inhibitory effect decreasing the voiding frequency without significantly changing other CMG parameters (Figs. 1E, 3). These experiments were performed in anesthetized rats where C-fiber afferents are involved in micturition (Cheng et al., 1993), and the effects of OxoM were absent in capsaicin pretreated rats (Fig. 6), suggesting that $\mathrm{mAChR}$ activation affects $\mathrm{C}$-fiber activity. NO contributed to the inhibitory effects because suppressing NO synthesis with L-NAME blunted the inhibition without altering the excitation (Fig. 7). The urothelium could be a source of NO because it releases NO in response to stimulation of various receptors (i.e., TRPV1 or $\beta$-adrenoreceptor) (Birder et al., 1998, 2002), although no study has shown NO release in response to $\mathrm{mAChR}$ stimulation. Because the bladder smooth muscle has low sensitivity to $\mathrm{NO}(\mathrm{Fu}-$ jiwara et al., 2000), the site of action of NO is likely the afferent neurons (Yoshimura et al., 2001) and/or the interstitial cells (Lagou et al., 2006). In dissociated bladder afferent neurons, NO donors modulate $\mathrm{N}$-type $\mathrm{Ca}^{2+}$ channels (Yoshimura et al., 2001) and in cultured C-type DRG neurons NO donors block fast TTXsensitive as well as slow and persistent TTX-resistant $\mathrm{Na}^{+}$cur- 

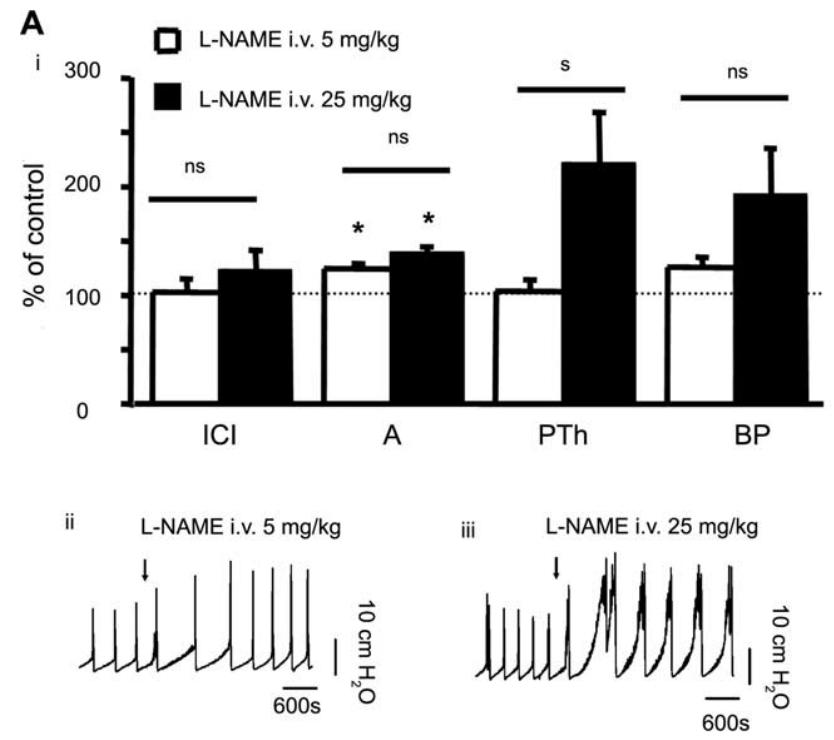

B

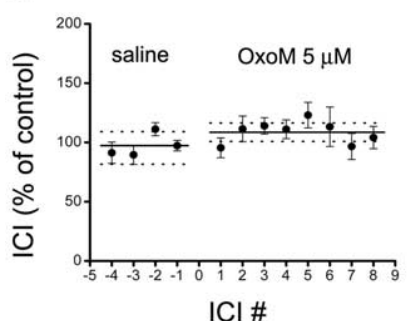

C

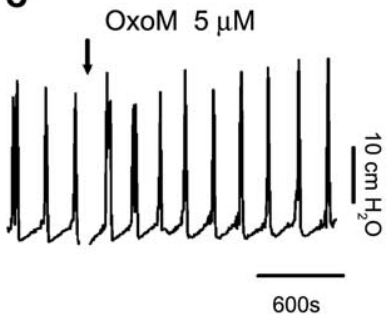

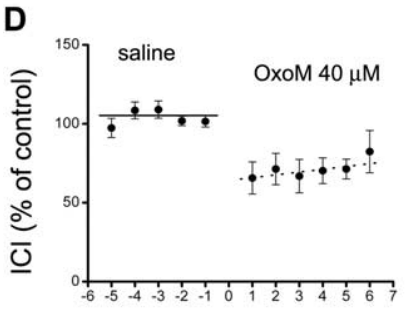

$\mathrm{ICI} \#$
$\mathbf{E}$

E

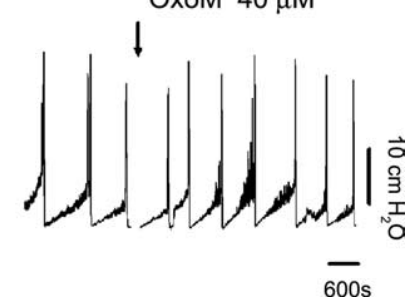

Figure 7. Inhibitory effects of intravesical administration of OxoM involve NO. Ai, Summary of the effects of intravenous administration of $5 \mathrm{mg} / \mathrm{kg}$ L-NAME (white bars; $n=9$ rats) and 25 $\mathrm{mg} / \mathrm{kg}$ L-NAME (black bars; $n=6$ rats) on CMG parameters. Asterisks represent significant changes from control (paired $t$ test between control and L-NAME $p<0.05$ ). Significant (s; unpaired $t$ test $p<0.05$ ) or nonsignificant (ns; unpaired $t$ test $p>0.05$ ) differences in between $5 \mathrm{mg} / \mathrm{kg}$ L-NAME and $25 \mathrm{mg} / \mathrm{kg}$ L-NAME are shown. Aii, Effects of $5 \mathrm{mg} / \mathrm{kg}$ (i.v.) L-NAME on CMG parameters. Aiii, Effects of $25 \mathrm{mg} / \mathrm{kg}$ (i.v.) L-NAME on CMG parameters. Arrows indicate the time when L-NAME (i.v.) was injected. $\boldsymbol{B}$, Time course of the effects of intravesical administration of low concentrations of $0 \times 0 M(5 \mu \mathrm{m})$ in rats treated with L-NAME ( $n=7$ rats). Negative ICI values represent the ICI number (\#) before $0 x 0$ M application and positive ICl values represent ICI \# after 0xoM application. ICI \# 0 was taken when 0 xoM was applied. C, The effects of intravesical administration of low concentrations of $0 \times 0 M(5 \mu \mathrm{M})$ on CMG parameters after L-NAME, illustrating the absence of $0 \times 0 M$-induced inhibition. $\boldsymbol{D}$, Time dependence of the effects of high concentrations of $0 \times 0 \mathrm{M}(40 \mu \mathrm{M})$ in rats treated with L-NAME ( $n=6$ rats). $\boldsymbol{E}$, The effects of 40 $\mu \mathrm{M}$ OxOM on CMG parameters after L-NAME illustrating the presence of OxoM-induced excitation.

rents (Renganathan et al., 2002), thereby affecting neuronal excitability.

\section{Excitatory mechanisms}

Intravesical administration of OxoM at concentrations $>20 \mu \mathrm{M}$ produced a predominant excitatory effect on ICI without signif- icantly changing other CMG parameters (Figs. $1 E, 4$ ), consistent with previous findings using carbachol (Kim et al., 2005). These effects were dependent on C-fiber activation as they were abolished in capsaicin pretreated animals (Fig. 6). One mechanism contributing to these effects is ATP release from the urothelium, followed by activation of purinergic receptors on afferent nerves. This is supported by our data demonstrating that (1) cultured urothelial cells release ATP after stimulation with OxoS (Fig. $8 D, E)$ and (2) blocking purinergic receptors in vivo with PPADS reduced the excitatory effects of OxoM (Fig. $8 A-C$ ). Other studies have shown that $\mathrm{P} 2 \mathrm{X}_{2 / 3}$ are expressed on bladder afferent nerves and that ATP released during bladder stretch or ATP administered intravesically can activate afferent nerves, triggering the micturition reflex (Ferguson et al., 1997; Cockayne et al., 2000; Vlaskovska et al., 2001; Pandita and Andersson, 2002; Kumar et al., 2004; Nishiguchi et al., 2005; Burnstock, 2006; Ruggieri, 2006). P2X and P2Y receptors are also expressed in urothelial cells (Birder et al., 2004) and myofibroblasts (Wu et al., 2004; Sui et al., 2006) and their activation may trigger ATP release, that can further stimulate the afferent nerves (Birder and de Groat, 2007).

The excitatory effects displayed two phases, an initial large decrease in the ICI followed by a smaller decrease in the ICI (Fig. 4). This could be interpreted as initial excitation followed by inhibition or two excitatory pathways one of which rapidly desensitizes. Blocking $\mathrm{NO}$ synthesis (Fig. $7 D, E$ ) or blocking purinergic receptors (Fig. $8 A-C$ ) did not affect the two-phase response, suggesting different mechanisms. One possibility involves activation of distinct $\mathrm{mAChR}$ subtypes located at different sites: urothelium and afferent nerves.

\section{Sensory role of urothelial and afferent nerve mAChRs and pathological implications}

The role of urothelium in bladder sensory mechanisms has recently attracted considerable attention. Historically this tissue has been viewed as a passive physical barrier preventing the leak of urine constituents into the bladder wall. Previous research indicating that urothelial cells express various receptors and release neurotransmitters in response to mechanical and chemical stimuli that could influence the excitability of the nerves suggests that the urothelium may play an active role in modulating bladder functions (Birder and de Groat, 2007). Our data provide evidence for such a role by demonstrating that activation of mAChRs located near the luminal surface of the bladder can modulate bladder reflexes via mechanisms involving $\mathrm{NO}$ and ATP, likely released from the urothelium and acting on C-fiber afferents to alter their excitability.

Intravesical AMN had no effect on voiding frequency (Fig. 2), suggesting that under normal physiological conditions urothelial and/or suburothelial mAChRs are not tonically active. However, OxoM-induced increases in voiding frequency resemble the pathological condition of overactive bladder $(\mathrm{OAB})$, suggesting that alteration of $\mathrm{mAChRs}$ in sensory pathways might contribute to some of the $\mathrm{OAB}$ symptoms. In the urothelium, alteration of $\mathrm{mAChRs} \mathrm{might} \mathrm{lead} \mathrm{to} \mathrm{increased} \mathrm{ATP} \mathrm{release.} \mathrm{Indeed,} \mathrm{in} \mathrm{bladders}$ that are overactive as a result of inflammation (Smith et al., 2005) or SCI (Salas et al., 2007) and in urothelial cells from patients or cats suffering from interstitial cystitis (Birder et al., 2003; Sun and Chai, 2006), ATP release is upregulated. In the afferent system, increased excitability of primary sensory neurons occurring after SCI or cystitis is considered a "fingerprint" of bladder hyperactivity (de Groat and Yoshimura, 2006). mAChRs might be involved in these changes as preliminary studies indicate that mus- 
carinic agonists can alter the firing properties of bladder afferent neurons (Negoita et al., 2004). Further investigation of the underlying muscarinic modulatory mechanisms, specifically whether a particular mAChR subtype $\left(\mathrm{M}_{1}-\mathrm{M}_{5}\right)$ or a $\mathrm{mAChR}$ subtype located at a particular site (urothelium or nerves) is involved, might help to identify new targets for the treatment of overactive bladder.

\section{References}

Abrams P, Andersson KE, Buccafusco JJ, Chapple C, de Groat WC, Fryer AD, Kay G, Laties A, Nathanson NM, Pasricha PJ, Wein AJ (2006) Muscarinic receptors: their distribution and function in body systems, and the implications for treating overactive bladder. Br J Pharmacol 148:565-578.

Bennett BC, Kruse MN, Roppolo JR, Flood HD, Fraser M, de Groat WC (1995) Neural control of urethral outlet activity in vivo: role of nitric oxide. J Urol 153:2004-2009.

Birder LA, de Groat WC (2007) Mechanisms of disease: involvement of the urothelium in bladder dysfunction. Nat Clin Pract Urol 4:46-54.

Birder LA, Apodaca G, De Groat WC, Kanai AJ (1998) Adrenergic- and capsaicin-evoked nitric oxide release from urothelium and afferent nerves in urinary bladder. Am J Physiol 275:F226-F229.

Birder LA, Nealen ML, Kiss S, de Groat WC, Caterina MJ, Wang E, Apodaca G, Kanai AJ (2002) Beta-adrenoceptor agonists stimulate endothelial nitric oxide synthase in rat urinary bladder urothelial cells. J Neurosci 22:8063-8070.

Birder LA, Barrick SR, Roppolo JR, Kanai AJ, de Groat WC, Kiss S, Buffington CA (2003) Feline interstitial cystitis results in mechanical hypersensitivity and altered ATP release from bladder urothelium. Am J Physiol Renal Physiol 285:F423-F429.

Birder LA, Ruan HZ, Chopra B, Xiang Z, Barrick S, Buffington CA, Roppolo JR, Ford AP, de Groat WC, Burnstock G (2004) Alterations in P2X and $\mathrm{P} 2 \mathrm{Y}$ purinergic receptor expression in urinary bladder from normal cats and cats with interstitial cystitis. Am J Physiol Renal Physiol 287:F1084-F1091.

Braverman AS, Kohn IJ, Luthin GR, Ruggieri MR (1998) Prejunctional M1 facilitory and M2 inhibitory muscarinic receptors mediate rat bladder contractility. Am J Physiol 274:R517-R523.

Burnstock G (2006) Purinergic P2 receptors as targets for novel analgesics. Pharmacol Ther 110:433-454.

Chaiyaprasithi B, Mang CF, Kilbinger H, Hohenfellner M (2003) Inhibition of human detrusor contraction by a urothelium derived factor. J Urol 170:1897-1900.

Cheng CL, Ma CP, de Groat WC (1993) Effects of capsaicin on micturition and associated reflexes in rats. Am J Physiol 265:R132-R138.

Cockayne DA, Hamilton SG, Zhu QM, Dunn PM, Zhong Y, Novakovic S, Malmberg AB, Cain G, Berson A, Kassotakis L, Hedley L, Lachnit WG, Burnstock G, McMahon SB, Ford AP (2000) Urinary bladder hyporeflexia and reduced pain-related behaviour in P2X3-deficient mice. Nature 407:1011-1015.

de Groat WC, Yoshimura N (2006) Mechanisms underlying the recovery of lower urinary tract function following spinal cord injury. Prog Brain Res 152:59-84.

de Groat WC, Giesselman BR, Sun L, Humphrey AL (2004) Role of urothelial muscarinic receptors in the control of voiding in rats. Soc Neurosci Abstr 30:950.19.
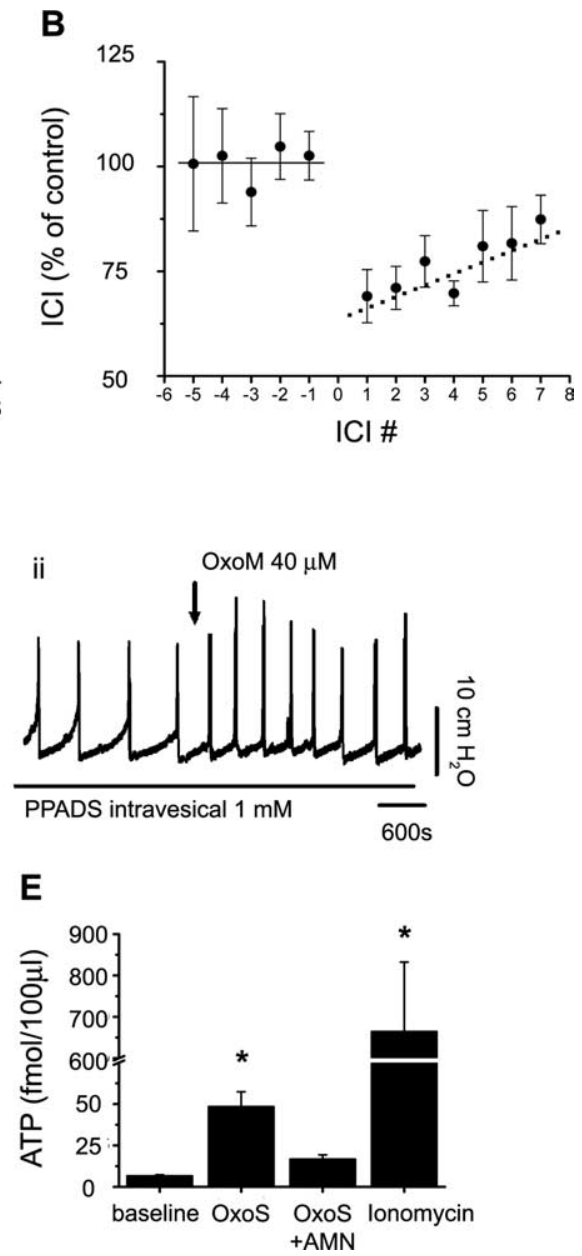

Figure 8. Mechanisms of the excitatory effects of intravesical administration of $0 \times 0 M$. $A$, The excitatory effect of $0 \times 0 \mathrm{M}$

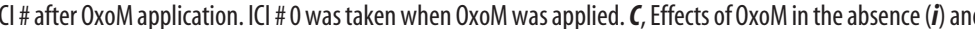

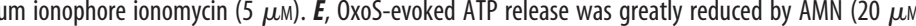
summary from $n=5$ coverslips). In $\boldsymbol{D}$ and $\boldsymbol{E}$, asterisks indicate significant differences tested with ANOVA between groups followed by Newman-Keuls post hoc test.

Ferguson DR, Kennedy I, Burton TJ (1997) ATP is released from rabbit urinary bladder epithelial cells by hydrostatic pressure changes-a possible sensory mechanism? J Physiol (Lond) 505:503-511.

Finney SM, Andersson KE, Gillespie JI, Stewart LH (2006) Antimuscarinic drugs in detrusor overactivity and the overactive bladder syndrome: motor or sensory actions? BJU Int 98:503-507.

Fujiwara M, Andersson K, Persson K (2000) Nitric oxide-induced cGMP accumulation in the mouse bladder is not related to smooth muscle relaxation. Eur J Pharmacol 401:241-250.

Gabella G, Davis C (1998) Distribution of afferent axons in the bladder of rats. J Neurocytol 27:141-155.

Giglio D, Ryberg AT, To K, Delbro DS, Tobin G (2005) Altered muscarinic receptor subtype expression and functional responses in cyclophosphamide induced cystitis in rats. Auton Neurosci 122:9-20.

Hawthorn MH, Chapple CR, Cock M, Chess-Williams R (2000) Urothelium-derived inhibitory factor (s) influences on detrusor muscle contractility in vitro. Br J Pharmacol 129:416-419.

Hegde SS, Choppin A, Bonhaus D, Briaud S, Loeb M, Moy TM, Loury D, Eglen RM (1997) Functional role of M2 and M3 muscarinic receptors in 
the urinary bladder of rats in vitro and in vivo. $\mathrm{Br} \mathrm{J}$ Pharmacol 120:1409-1418.

Ishiura Y, Yoshiyama M, Yokoyama O, Namiki M, de Groat WC (2001) Central muscarinic mechanisms regulating voiding in rats. J Pharmacol Exp Ther 297:933-939.

Kanai A, Roppolo J, Ikeda Y, Zabbarova I, Tai C, Birder L, Griffiths D, de Groat W, Fry C (2007) Origin of spontaneous activity in neonatal and adult rat bladders and its enhancement by stretch and muscarinic agonists. Am J Physiol Renal Physiol 292:F1065-F1072.

Kim Y, Yoshimura N, Masuda H, de Miguel F, Chancellor MB (2005) Antimuscarinic agents exhibit local inhibitory effects on muscarinic receptors in bladder-afferent pathways. Urology 65:238-242.

Kullmann FA, Artim DE, Beckel J, Barrick S, de Groat WC, Birder LA (2008) Heterogeneity of muscarinic receptor mediated $\mathrm{Ca}^{2+}$ responses in cultured urothelial cells from rat. Am J Physiol Renal Physiol, in press.

Kumar V, Chapple CC, Chess-Williams R (2004) Characteristics of adenosine triphosphate release from porcine and human normal bladder. J Urol 172:744-747.

Lagou M, Drake MJ, Markerink-VAN Ittersum M, DE Vente J, Gillespie JI (2006) Interstitial cells and phasic activity in the isolated mouse bladder. BJU Int 98:643-650.

Lecci A, Carini F, Tramontana M, Birder LA, de Groat WC, Santicioli P, Giuliani S, Maggi CA (2001) Urodynamic effects induced by intravesical capsaicin in rats and hamsters. Auton Neurosci 91:37-46.

Mansfield KJ, Liu L, Mitchelson FJ, Moore KH, Millard RJ, Burcher E (2005) Muscarinic receptor subtypes in human bladder detrusor and mucosa, studied by radioligand binding and quantitative competitive RT-PCR: changes in ageing. Br J Pharmacol 144:1089-1099.

Masuda H, Ogawa T, Kihara K, Chancellor MB, de Groat WC, Yoshimura N (2007) Effects of anaesthesia on the nitrergic pathway during the micturition reflex in rats. BJU Int 100:175-180.

Mukerji G, Yiangou Y, Grogono J, Underwood J, Agarwal SK, Khullar V, Anand P (2006) Localization of M2 and M3 muscarinic receptors in human bladder disorders and their clinical correlations. J Urol 176:367-373.

Negoita FA, Beckel JM, Birder LA, de Groat WC (2004) Effects of muscarinic receptor agonists on lumbosacral dorsal root ganglion cells. Soc Neurosci Abstr 30:950.9.

Nishiguchi J, Hayashi Y, Chancellor MB, de Miguel F, de Groat WC, Kumon H, Yoshimura N (2005) Detrusor overactivity induced by intravesical application of adenosine 5 '-triphosphate under different delivery conditions in rats. Urology 66:1332-1337.

Ozawa H, Chancellor MB, Jung SY, Yokoyama T, Fraser MO, Yu Y, de Groat WC, Yoshimura N (1999) Effect of intravesical nitric oxide therapy on cyclophosphamide-induced cystitis. J Urol 162:2211-2216.

Pandita RK, Andersson KE (2002) Intravesical adenosine triphosphate stimulates the micturition reflex in awake, freely moving rats. J Urol 168:1230-1234.

Pandita RK, Mizusawa H, Andersson KE (2000) Intravesical oxyhemoglobin initiates bladder overactivity in conscious, normal rats. J Urol 164:545-550.

Renganathan M, Cummins TR, Waxman SG (2002) Nitric oxide blocks fast, slow, and persistent $\mathrm{Na}+$ channels in C-type DRG neurons by S-nitrosylation. J Neurophysiol 87:761-775.
Ruggieri Sr MR (2006) Mechanisms of disease: role of purinergic signaling in the pathophysiology of bladder dysfunction. Nat Clin Pract Urol 3:206-215.

Salas NA, Somogyi GT, Gangitano DA, Boone TB, Smith CP (2007) Receptor activated bladder and spinal ATP release in neurally intact and chronic spinal cord injured rats. Neurochem Int 50:345-350.

Santicioli P, Maggi CA, Meli A (1985) The effect of capsaicin pretreatment on the cystometrograms of urethane anesthetized rats. J Urol 133:700-703.

Smith CP, Vemulakonda VM, Kiss S, Boone TB, Somogyi GT (2005) Enhanced ATP release from rat bladder urothelium during chronic bladder inflammation: effect of botulinum toxin A. Neurochem Int 47:291-297.

Somogyi GT, de Groat WC (1992) Evidence for inhibitory nicotinic and facilitatory muscarinic receptors in cholinergic nerve terminals of the rat urinary bladder. J Auton Nerv Syst 37:89-97.

Somogyi GT, Tanowitz M, de Groat WC (1994) M1 muscarinic receptormediated facilitation of acetylcholine release in the rat urinary bladder. J Physiol (Lond) 480:81-89.

Sugaya K, Ogawa Y, Nishizawa O, de Groat WC (1997) Decrease in intravesical saline volume during isovolumetric cystometry in the rat. Neurourol Urodyn 16:125-132.

Sui GP, Wu C, Fry CH (2006) Characterization of the purinergic receptor subtype on guinea-pig suburothelial myofibroblasts. BJU Int 97:1327-1331.

Sun Y, Chai TC (2006) Augmented extracellular ATP signaling in bladder urothelial cells from patients with interstitial cystitis. Am J Physiol Cell Physiol 290:C27-C34.

Takeda H, Yamazaki Y, Igawa Y, Kaidoh K, Akahane S, Miyata H, Nishizawa O, Akahane M, Andersson KE (2002) Effects of beta(3)-adrenoceptor stimulation on prostaglandin $\mathrm{E}(2)$-induced bladder hyperactivity and on the cardiovascular system in conscious rats. Neurourol Urodyn 21:558-565.

Tyagi S, Tyagi P, Van-le S, Yoshimura N, Chancellor MB, de Miguel F (2006) Qualitative and quantitative expression profile of muscarinic receptors in human urothelium and detrusor. J Urol 176:1673-1678.

Vlaskovska M, Kasakov L, Rong W, Bodin P, Bardini M, Cockayne DA, Ford AP, Burnstock G (2001) P2X3 knock-out mice reveal a major sensory role for urothelially released ATP. J Neurosci 21:5670-5677.

Wu C, Sui GP, Fry CH (2004) Purinergic regulation of guinea pig suburothelial myofibroblasts. J Physiol (Lond) 559:231-243.

Yoshimura N, Seki S, de Groat WC (2001) Nitric oxide modulates $\mathrm{Ca}^{2+}$ channels in dorsal root ganglion neurons innervating rat urinary bladder. J Neurophysiol 86:304-311.

Yu Y, de Groat WC (1999) Effects of ZD6169, a K(ATP) channel opener, on the micturition reflex in the rat. J Pharmacol Exp Ther 290:825-831.

Zarghooni S, Wunsch J, Bodenbenner M, Bruggmann D, Grando SA, Schwantes U, Wess J, Kummer W, Lips KS (2007) Expression of muscarinic and nicotinic acetylcholine receptors in the mouse urothelium. Life Sci 80:2308-2313.

Zhou H, Meyer A, Starke K, Gomeza J, Wess J, Trendelenburg AU (2002) Heterogeneity of release-inhibiting muscarinic autoreceptors in heart atria and urinary bladder: a study with $\mathrm{M}(2)$ - and $\mathrm{M}(4)$-receptordeficient mice. Naunyn Schmiedebergs Arch Pharmacol 365:112-122. 